\title{
Analysis of Squeezing Phenomenon in the Headrace Tunnel of Chameliya Project, Nepal
}

Chhatra Bahadur Basnet, Pawan Kumar Shrestha and Krishna Kanta Panthi

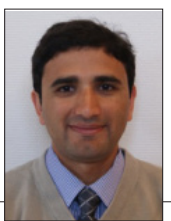

Chhatra Bahadur Basnet

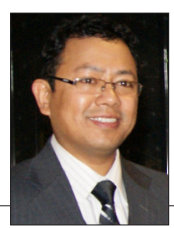

Pawan Kumar Shrestha

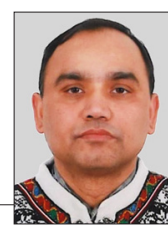

Krishna Kanta Panthi

Abstract: The headrace tunnel of Chameliya Hydroelectric Project, Nepal has faced severe squeezing problems from chainage $3+100 \mathrm{~m}$ to $3+900 \mathrm{~m}$. Due to the severe squeezing and deformation, the tunnel cross section has narrowed considerably along this $800 \mathrm{~m}$ long tunnel stretch. The tunnel wall closure (deformation) is mostly well over $1 \mathrm{~m}$ and the maximum recorded closure exceeds $2 \mathrm{~m}$. This paper assesses the squeezing phenomenon along this tunnel stretch through evaluation of rock mass properties and support pressure. Three different methods (two analytical and one 2D finite element numerical modeling program) are used in this analysis. The finding is that it is possible to predict extent of squeezing in tunnel if more than one method is used to verify rock mass mechanical properties.

Key words: Tunnel squeezing, Headrace tunnel, Chameliya Hydroelectric Project, tunnel deformation, support pressure

\section{Introduction}

$\mathrm{U}$ tilization of underground space such as tunnels, shafts, and underground powerhouse caverns are necessary to harness hydro-electricity in a mountainous country like Nepal. At the same time, the design and placement of these structures encounter several risks and uncertainties in the associated geo-strata. Some of the major risks include in-situ stresses, ground water in the rock mass, and weakness and fault zones. When there is overstressing of rock mass (i.e., rock stress exceeds the strength of rock mass), stress induced instability occurs in the tunnel. If the rock mass is very weak, schistose and deformable, squeezing will occur, as a plastic zone develops around the tunnel causing excessive deformation in the tunnel periphery. In the Himalaya, tunnel squeezing is a common phenomenon (Panthi, 2006) as the fault zones and weak rocks (e.g., mudstone, shale, slate, phyllite, schist, highly schistose gneiss) that compose the mountains are not capable of withstanding high stress.

Excessive squeezing has occurred along the headrace tunnel of Chameliya Hydroelectric Project. Combating the

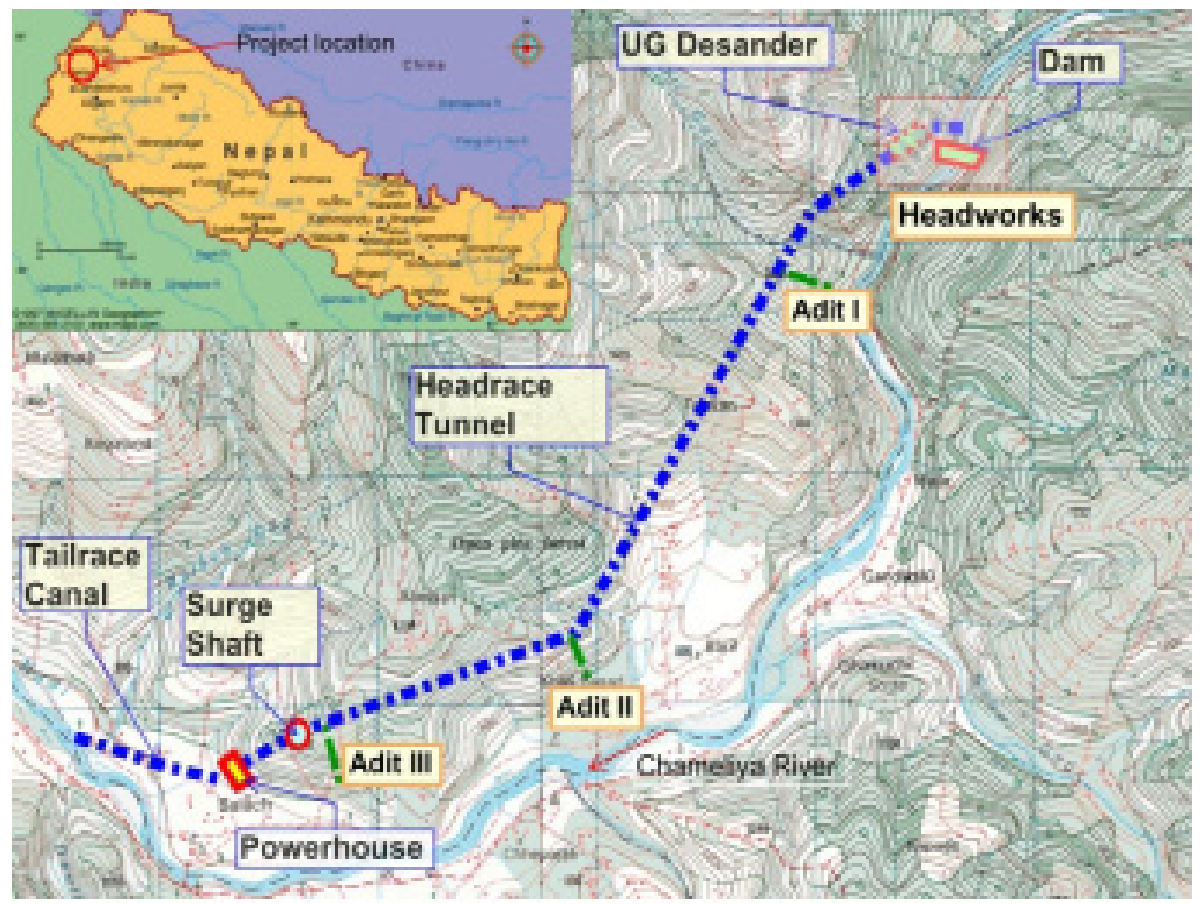
squeezing posed significant challenges to the project management. This paper assesses the squeezing phenomenon along the downstream stretch of the headrace tunnel at Chameliya and establishes rock mass mechanical characteristics of that area using both analytical and numerical modeling methods.

\section{Chameliya Hydroelectric Project}

Chameliya River is one of the major tributaries of Mahakali River. The Chameliya Hydroelectric Project (Figure 1) is located in Darchula district of the far western development region of Nepal. The project is located approximately $270 \mathrm{~km}$ northwest from Dhangadi, one of the major business centers in the western region. To cope with the growing power demands and to activate industrial growth in far western region of Nepal, the Government of Nepal gave high priority to develop the Chameliya Hydroelectric Project. The project has daily 
Central Thrust (MCT). The rocks in this area are folded and faulted. Two faults are inferred across the headrace tunnel alignment. A thrust fault lies between the contact of dolomite and sandstone near Bhel Gad about 6oom downstream of the dam site. The fault extends in the left bank of Chameliya Gad with

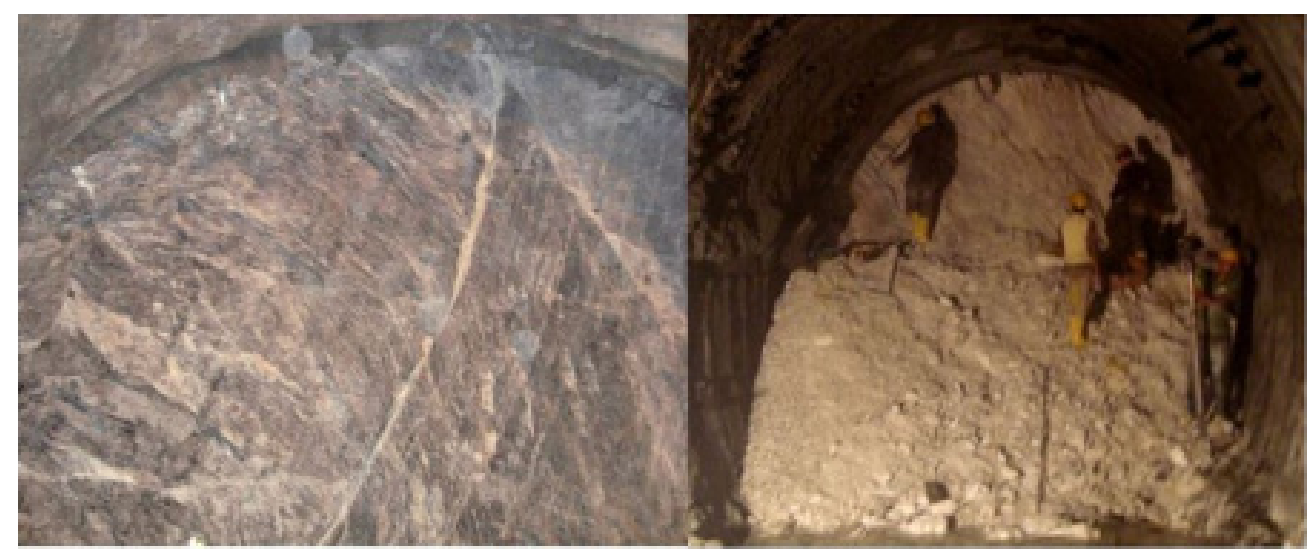

Figure 3. Rock mass condition at different chainage along the headrace tunnel highly fractured rock zone. Another fault in the contact of dolomite and slate is inferred and passes through Baril village following a large flow of spring to the right bank of Chameliya Gad.

The project area is covered by meta-sedimentary rock of Surkhet group and Midland group that consists of rocks such as siliceous dolomite, sandstone, calcareous slate, dolomite and dolomite intercalated with slate (NEA 1997). The general trend of the bedding/foliation is east to west and dips steeply north at the dam site with a gentle transition towards powerhouse site.

Figure 2 shows the geological plan and profile along the tunnel alignment of the project in the present condition. The cross-section of headrace tunnel is horseshoe shaped with a diameter of $5.2 \mathrm{~m} / 4.2 \mathrm{~m}$. The total headrace tunnel length is $4067 \mathrm{~m}$. As seen in the Figure 2, the main rock types along the headrace tunnel alignment are dolomite, dolomite intercalated with slate, talc phyllite, and dolomite intercalated with phyllite.

The left photo of Figure 3 shows thinly foliated and

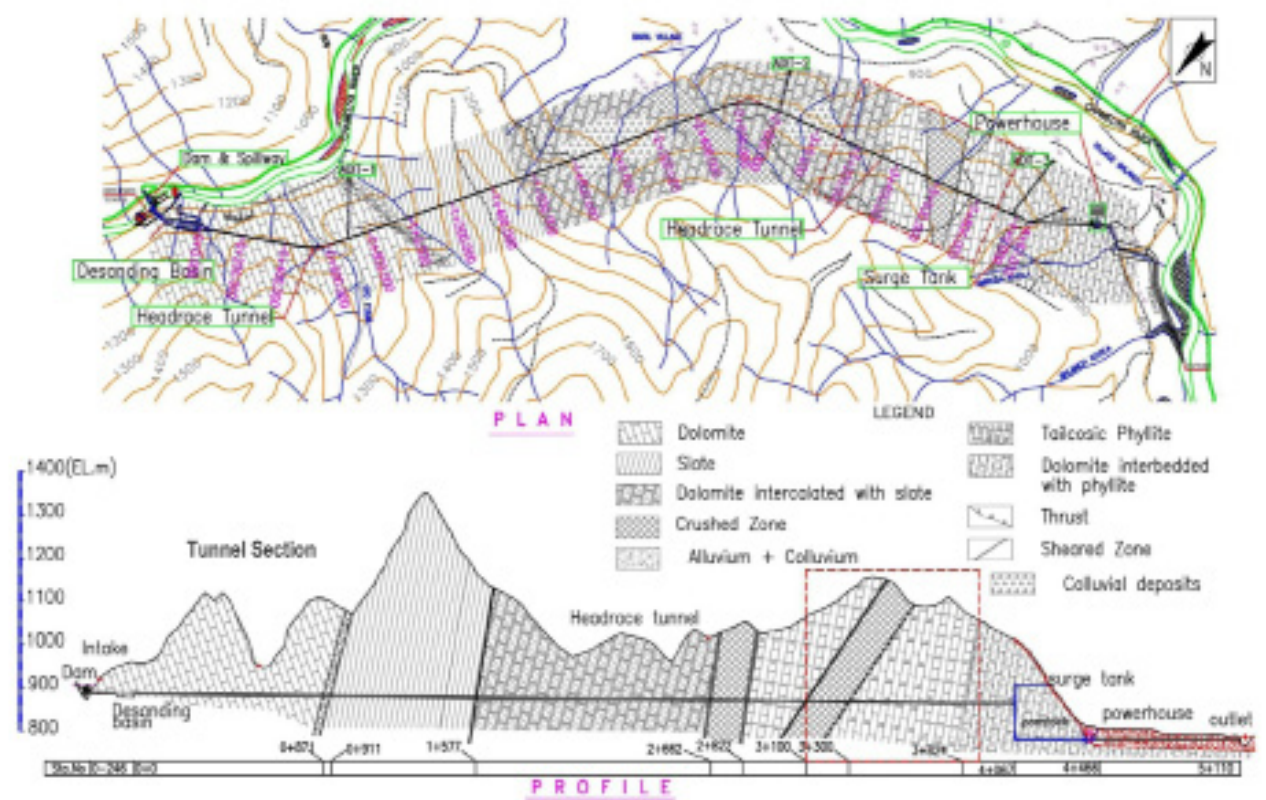

Figure 2. Geological Plan and Profile along the headrace tunnel alignment fractured dolomite and highly sheared and fractured talc phyllite with some bands of dolomite in the section between adit 2 and adit 3 . The rock mass condition in tunnel sections from chainage $0+000 \mathrm{~m}$ to $3+100 \mathrm{~m}$ is quite good with a few exceptions. However, from 8oom downstream of the headrace tunnel from chainage $3+100 \mathrm{~m}$ to $3+900 \mathrm{~m}$ (end of headrace tunnel), the rock mass morphs to extremely poor quality as shown in the right photo of Figure 3.

\section{Instability along the headrace tunnel}

During excavation, the headrace tunnel crossed different rocks, weakness zones, and faults. In the tunnel section from chainage $0+000$ to $3+100 m$, there were minor stability problems. The rock support built along this section is primarily composed of shotcrete with wire mesh and systematic rock bolting. But in the tunnel section from chainage $3+100 \mathrm{~m}$ to $3+900 \mathrm{~m}$, severe tunnel squeezing and even tunnel collapse were registered. The actual geology in this area was found to be significantly different from what had been predicted during feasibility and design. The main rock type along this tunnel section is talc phyllite, which has extremely poor rock mass quality. Figure 4 shows the headrace tunnel section between adit 2 and adit 3 where significant floor heaving and wall convergence were recorded. There were also several instances of large mud flows, floor heaving, and poor invert conditions that led to the stoppage of work for long periods during excavation.

Due to severe 


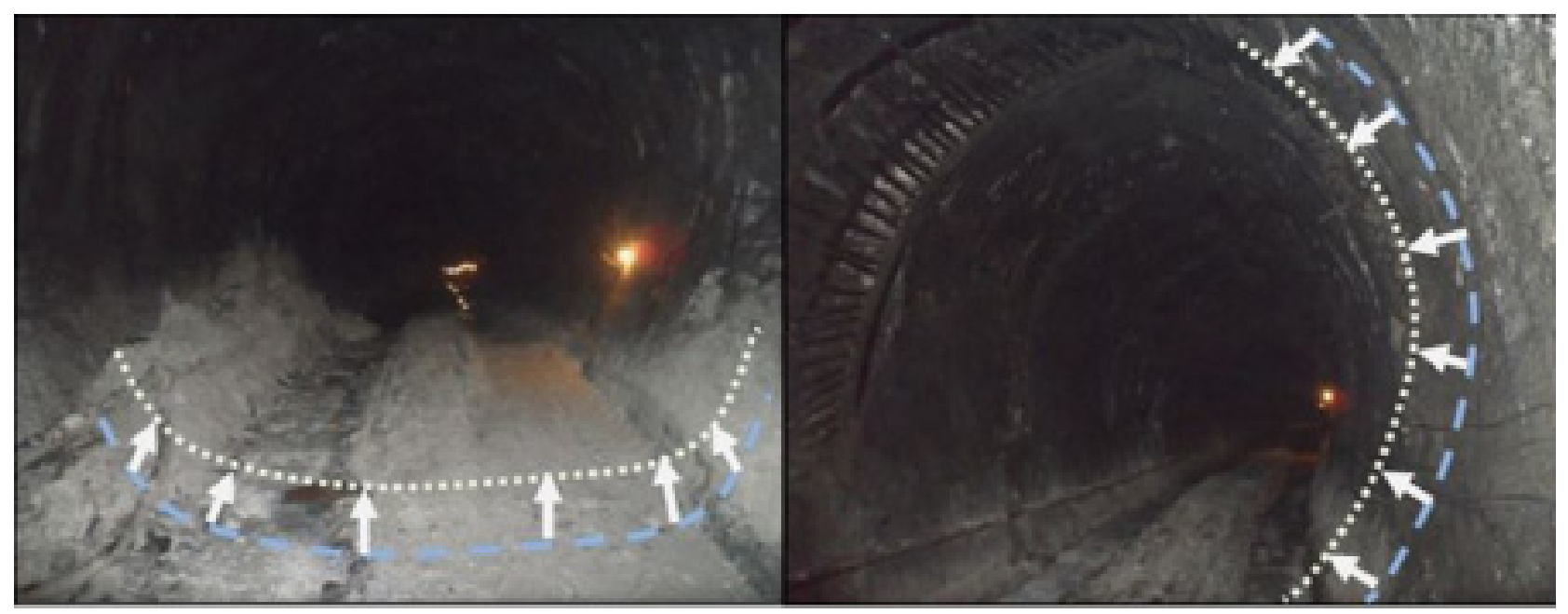

Figure 4. Tunnel squeezing in headrace tunnel of CHEP: Significant floor heave (left) and wall closure in hill side (right)

squeezing and the associated deformation, the tunnel cross section has been reduced considerably in several stretches of the headrace tunnel. At several locations, the tunnel wall closure (deformation) is well over $1 \mathrm{~m}$ with a maximum recorded deformation above $2 \mathrm{~m}$. The worst affected length of the tunnel is approximately $550 \mathrm{~m}$. Due to excessive deformation, temporary supports have been installed at several locations because the steel ribs and lattice girders have buckled at several locations and the shotcrete lining has been severely cracked. Today the squeezing in most of the sections has been stabilized but is still active in some places. The deformed tunnel profile is being monitored periodically. Closure of the tunnel wall has been measured in the tunnel sections using the survey data from this monitoring work.

\section{Tunnel excavation and support measures}

The headrace tunnel excavation was started in June 2008 and completed in May 2012. Tunnel section from chainage $0+000 \mathrm{~m}$ to $3+100 \mathrm{~m}$ was excavated with conventional drill and blast methodology. But for the sections with severe squeezing problems, alternative methods were required such as over excavation (unsuccessful), fore-poling, sequential excavation (top heading and benching), excavation through light and controlled blasting, and manual excavations.

During excavation, different rock support measures were applied along the length of the headrace tunnel. The main support types that were applied are categorized as rock class category R 5 and R6 as per site conditions where the Q-value is less than o.1. Table 1 shows the type of support applied based on rock mass quality (Q-value). As reinforcement, lattice girder was used in support category $\mathrm{R} 5$ while steel rib was installed for support category R6. In addition, rock support was also applied at the face of tunnel to improve working conditions for next sequence.

\begin{tabular}{|c|c|c|c|}
\hline $\begin{array}{c}\text { Rock } \\
\text { mass } \\
\text { Quality } \\
\text { (Q) }\end{array}$ & $10 \leq Q$ & $4 \leq Q<10$ & $1 \leq Q<4$ \\
\hline $\begin{array}{l}\text { Support } \\
\text { Pattern }\end{array}$ & Type-R1 & Type-R2 & Type-R3 \\
\hline Remarks & $\begin{array}{c}\text { Enforce a } \\
\text { spot bolting } \\
\text { in fragile part }\end{array}$ & $\begin{array}{l}\text { Pattern bolt- } \\
\text { ing unten- } \\
\text { sioned D25, } \\
\mathrm{L}=3.0 @ 1.50 \\
\text { Upper } 120^{\circ}\end{array}$ & $\begin{array}{l}\text { Pattern bolt- } \\
\text { ing unten- } \\
\text { sioned D25, } \\
\mathrm{L}=3.0 @ 1.50 \\
\text { Upper } 180^{\circ}\end{array}$ \\
\hline $\begin{array}{c}\text { Rock mass } \\
\text { Quality } \\
\text { (Q) }\end{array}$ & $0.1 \leq \mathrm{Q}<1$ & $\mathrm{Q}<1$ & $\mathrm{Q}<0.1$ \\
\hline $\begin{array}{l}\text { Support } \\
\text { Pattern }\end{array}$ & Type-R4 & Type-R5 & Type-R6 \\
\hline Remarks & $\begin{array}{c}\text { Pattern bolt- } \\
\text { ing unten- } \\
\text { sioned D25, } \\
\mathrm{L}=3.0 @ 1.50 \\
\text { Upper and } \\
\text { side wall } 240^{\circ}\end{array}$ & $\begin{array}{c}\text { Type-R4 } \\
\text { pattern and } \\
\text { lattice girder } \\
\text { support }\end{array}$ & $\begin{array}{l}\text { Type-R4 pattern } \\
\text { and steel rib } \\
\text { support }\end{array}$ \\
\hline
\end{tabular}

Table 1: Applied support type based on rock mass quality (Q-value)

Figure 5 shows the photographs that were taken during excavation and after excavation. The figure illustrates the support application at face (top left), application of fore poling (top right), instance of mud flow (bottom left) and application of temporary support at heavy squeezing sections (bottom right). The steel ribs and fore poling were applied at the face of tunnel and shotcrete with wire mesh was applied afterwards. The squeezing still continued even though careful measures had been taken. The bottom right photograph in Figure 5 shows the squeezed condition of tunnel where applied support measures had been installed.

\section{Squeezing Analysis}

The deformation of the tunnel was measured at points where the squeezing problem was visible. Regarding rock mass parameters, no tests were performed during 


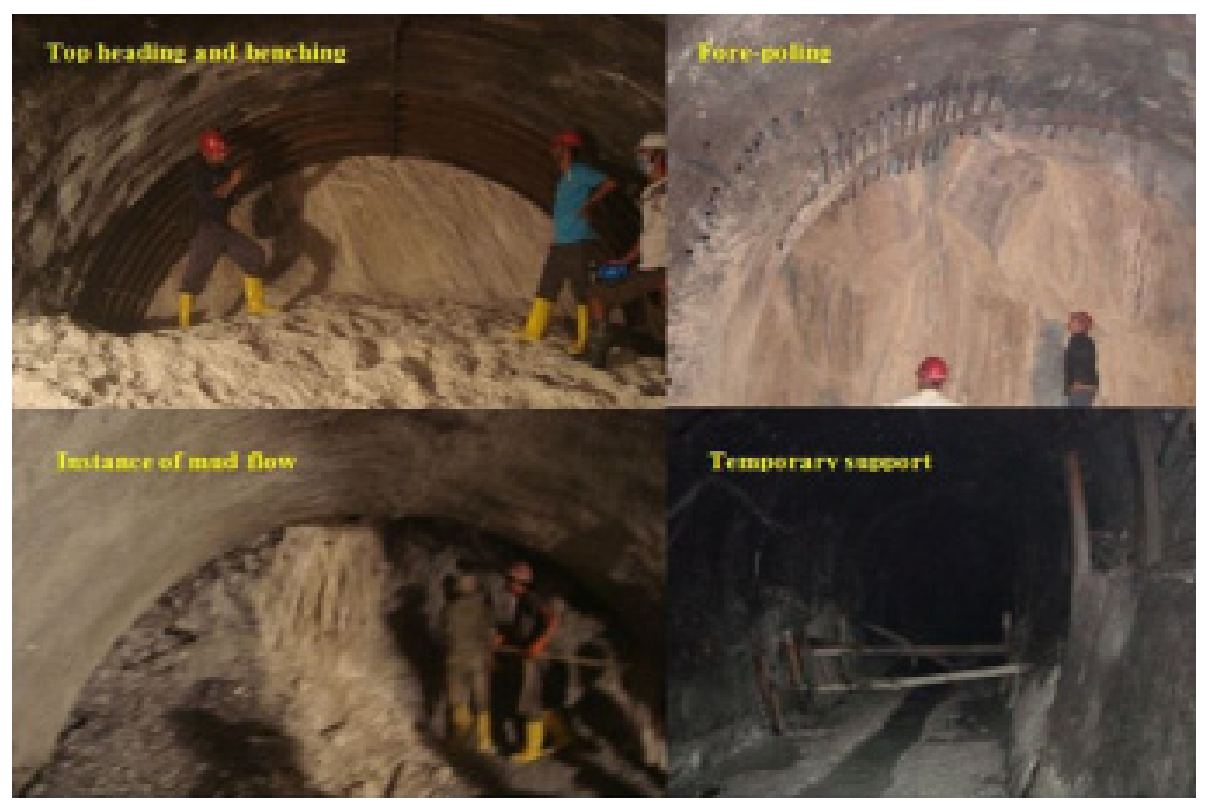

Figure 5. Several instances of tunnel excavation in CHEP at squeezing part

the study period nor at the time of excavation. Q-value was estimated at the face of tunnel during face mapping, and rock types and support types were also recorded. Other parameters, such as unconfined compressive strength of the intact rock, Young's modulus of the intact rock, density of the rock, and Poisson's ratio were not lab tested. Therefore, these parameters were estimated by drawing information from previously published reports of similar type of rocks from the Himalayan region (Basnet 2013).

Methods and approaches that have been used for the analysis of the squeezing phenomenon along the headrace tunnel are the semi-analytical Hoek and Marinos approach (Hoek and Marinos 2000), the analytical Convergence Confinement Method (Carranza-Torres and Fairhurst 2000) with the Hoek and Brown failure criteria (Hoek et al 2002) and 2D finite element numerical analysis using Phase $\mathrm{e}^{2}$. The methodology and equations that were used for each approach were drawn from respective literatures (for details see Basnet 2013). Ten sections were analyzed along the squeezed part of the headrace tunnel based on the established rock mass parameters as given in Table 2.

\begin{tabular}{|c|c|c|c|c|c|c|c|c|c|c|c|c|c|}
\hline 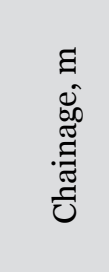 & 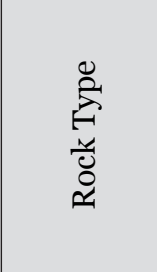 & 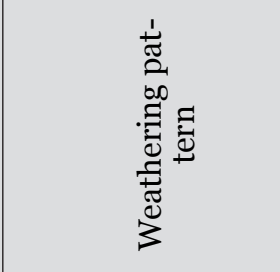 & 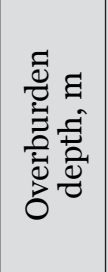 & 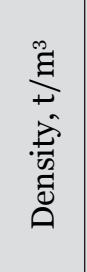 & 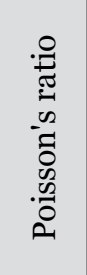 & 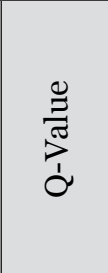 & 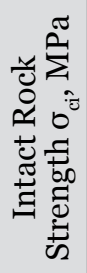 & 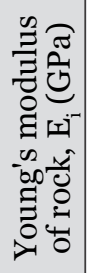 & 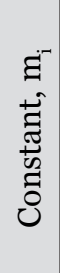 & 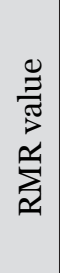 & છే & 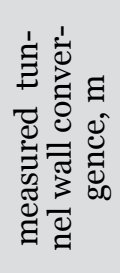 & 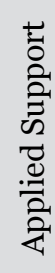 \\
\hline $3+172$ & Dolomite & highly weathered & 199.7 & 2.82 & 0.15 & 0.02 & 12 & 10 & 10 & 25 & 20 & 0.23 & $\mathrm{R} 5$ \\
\hline $3+190$ & Dolomite & highly weathered & 217.5 & 2.82 & 0.15 & 0.013 & 7 & 10 & 10 & 22 & 17 & 1.32 & $\mathrm{R} 5$ \\
\hline $3+296$ & $\begin{array}{l}\text { Talcosic } \\
\text { Phyllite }\end{array}$ & Highly Weathered & 252.2 & 2.78 & 0.10 & 0.01 & 14 & 7 & 8 & 20 & 15 & 0.65 & R6 \\
\hline $3+314$ & $\begin{array}{l}\text { Talcosic } \\
\text { Phyllite }\end{array}$ & Highly Weathered & 246.3 & 2.78 & 0.10 & 0.01 & 20 & 7 & 8 & 20 & 15 & 0.19 & R6 \\
\hline $3+404$ & $\begin{array}{l}\text { Talcosic } \\
\text { Phyllite }\end{array}$ & Highly weathered & 283.9 & 2.78 & 0.10 & 0.008 & 10 & 7 & 8 & 19 & 14 & 1.91 & R6 \\
\hline $3+420$ & $\begin{array}{l}\text { Talcosic } \\
\text { Phyllite }\end{array}$ & Highly weathered & 284.5 & 2.78 & 0.10 & 0.008 & 11 & 7 & 8 & 19 & 14 & 1.56 & R6 \\
\hline $3+681$ & $\begin{array}{l}\text { Talcosic } \\
\text { Phyllite }\end{array}$ & Highly weathered & 210.8 & 2.78 & 0.10 & 0.01 & 10 & 7 & 8 & 20 & 15 & 0.95 & R6 \\
\hline $3+733$ & $\begin{array}{l}\text { Talcosic } \\
\text { Phyllite }\end{array}$ & $\begin{array}{l}\text { Moderately } \\
\text { weathered }\end{array}$ & 237.7 & 2.78 & 0.10 & 0.01 & 14 & 7 & 8 & 20 & 15 & 0.56 & R6 \\
\hline $3+764$ & $\begin{array}{l}\text { Talcosic } \\
\text { Phyllite }\end{array}$ & $\begin{array}{l}\text { Moderately } \\
\text { weathered }\end{array}$ & 230.0 & 2.78 & 0.10 & 0.015 & 12 & 7 & 8 & 23 & 18 & 0.50 & $\mathrm{R}_{5}$ \\
\hline $3+795$ & $\begin{array}{l}\text { Talcosic } \\
\text { Phyllite }\end{array}$ & $\begin{array}{l}\text { Moderately } \\
\text { weathered }\end{array}$ & 222.6 & 2.78 & 0.10 & 0.015 & 23 & 7 & 8 & 23 & 18 & 0.06 & $\mathrm{R} 5$ \\
\hline
\end{tabular}

Table 2: Input parameters for squeezing analysis of selected tunnel sections 
The following two equations have been used to calculate plastic zone radius and tunnel wall deformation $\left(d_{i}\right)$ as suggested by Hoek and Marinos (2000):

$$
\begin{aligned}
& \frac{d_{p}}{d_{o}}=\left(1.25-0.625 \frac{p_{i}}{p_{o}}\right) \frac{\sigma_{\mathrm{cm}}}{p_{o}}\left(\frac{p_{l}}{p_{o}}-0.57\right) \\
& \frac{\delta_{i}}{d_{o}}=\left(0.002-0.0025 \frac{p_{i}}{p_{o}}\right) \frac{\sigma_{c m}}{p_{o}}\left(2.4 \frac{p_{l}}{p_{o}}-2\right)
\end{aligned}
$$

Where,

$d_{p}=$ Plastic zone diameter

$d_{o}=$ Original tunnel diameter in meters

$\delta_{i}=$ Tunnel sidewall deformation

$p_{i}=$ internal support pressure

$p_{o}=$ In situ stress (gravity stress)

$\sigma_{c m}=$ Rock mass strength

This method and our analysis make basic assumptions as1) a simple closed-form solution for a circular tunnel in a hydrostatic stress field; 2) support acts uniformly on entire perimeter of the tunnel. It should be noted that these conditions are seldom met in the field, and that tunnel shape and in-situ stress conditions are seldom as simple as those assumed. Therefore, where there is potential for a squeezing problem it is recommended that numerical analysis should also be carried out to so as to ascertain the results calculated by empirical, semiempirical and analytical solutions.

Hoek and Marinos (2000) suggested five classifications of squeezing to describe the range of severity (few support problems to extreme) based on the tunnel strain percentages. The ranges of these classes and their description are shown in Figure 6.

This approach has been used to find the percentage

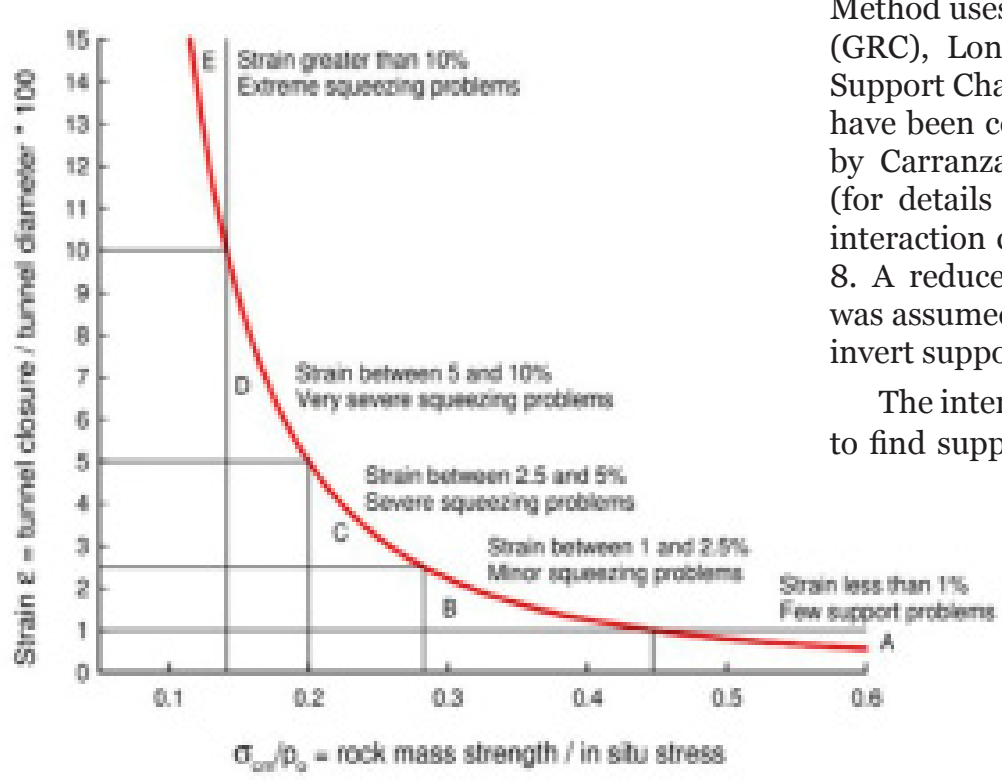

Figure 6. Approximate relationship between strain and the degree of difficulty associated with tunneling through squeezing rock in the case of unsupported tunnel (Hoek and Marinos 2000) strain in ten tunnel sections. Based on Hoek and Marinos classification in Figure 6, tunnel strain values were calculated, measured, and compared. According to this approach, it was found that there would be severe squeezing in one section, very severe squeezing in two sections, and extreme squeezing in seven sections (these findings are plotted in Figure 7). The measured values also show similar squeezing classes, which validates the Hoek and Marinos (2000) approach and the input variables used for calculation appear close to actual characteristics.

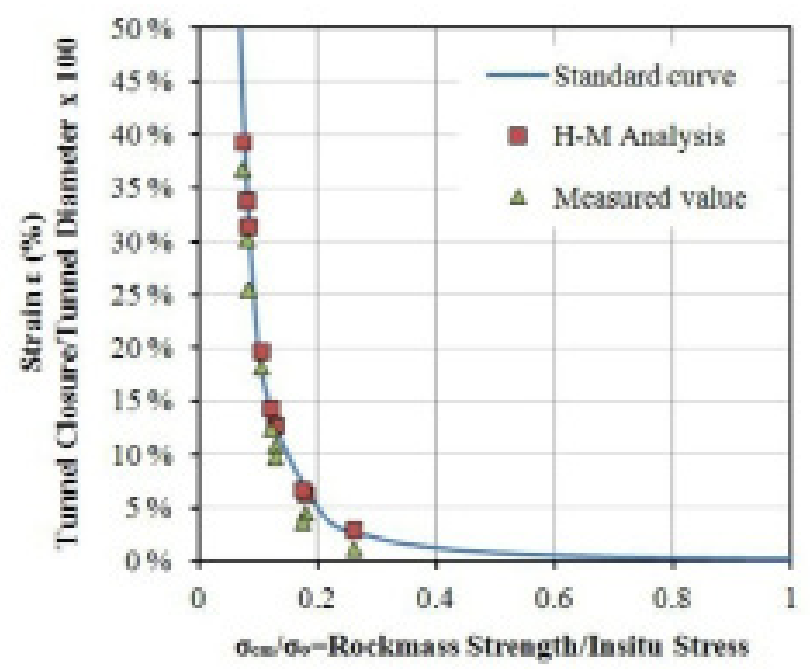

Figure 7. Calculated tunnel strain versus ratio of rock mass strength and gravity stress at the Chameliya Project Headrace Tunnel.

Furthermore, the Hoek and Marinos (HM) approach and Convergence Confinement Method (CCM) have been used to find out support pressure, radius of plastic zone, and tunnel wall deformation. Convergence Confinement Method uses three components: Ground Reaction Curve (GRC), Longitudinal Displacement Profile (LDP) and Support Characteristics Curve (SCC). These three curves have been constructed using different formulae devised Carranza-Torres and Fairhurst (2000) and others see Basnet, 2013). A typical rock support was assumed for the horseshoe section that did not have Tupport.

The interaction of these three curves has been plotted pressure and tunnel wall deformations. Figure 9 and 10 show support pressure and radius of plastic zone, respectively, using both Hoek and Marinos (2000) and Convergence Confinement Methods.

In the case of Hoek and Marinos (2000), the support pressure has been estimated for cases at $2 \%$ tunnel strain condition and actually measured tunnel closures. Similarly, in case of CCM, the support pressure has been estimated at the face of the tunnel, $1 \mathrm{~m}$ behind the tunnel face, $2 \mathrm{~m}$ 


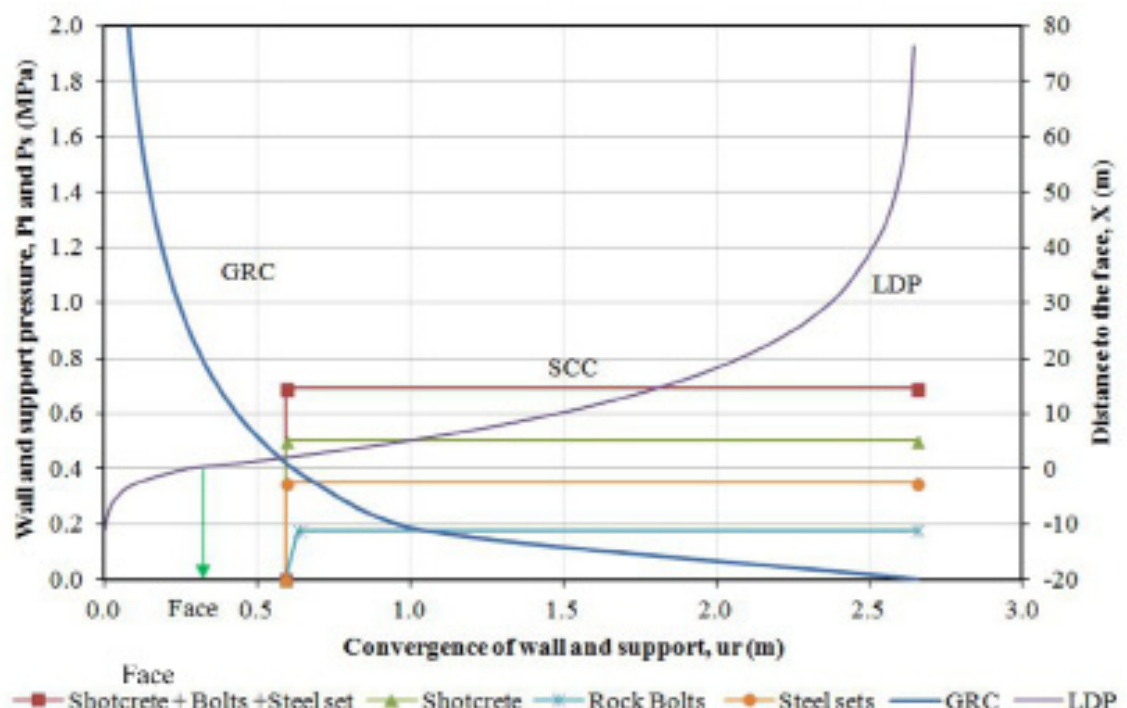

Figure 8. Interaction of GRC, LDP and SCC in tunnel section $3+404 \mathrm{~m}$
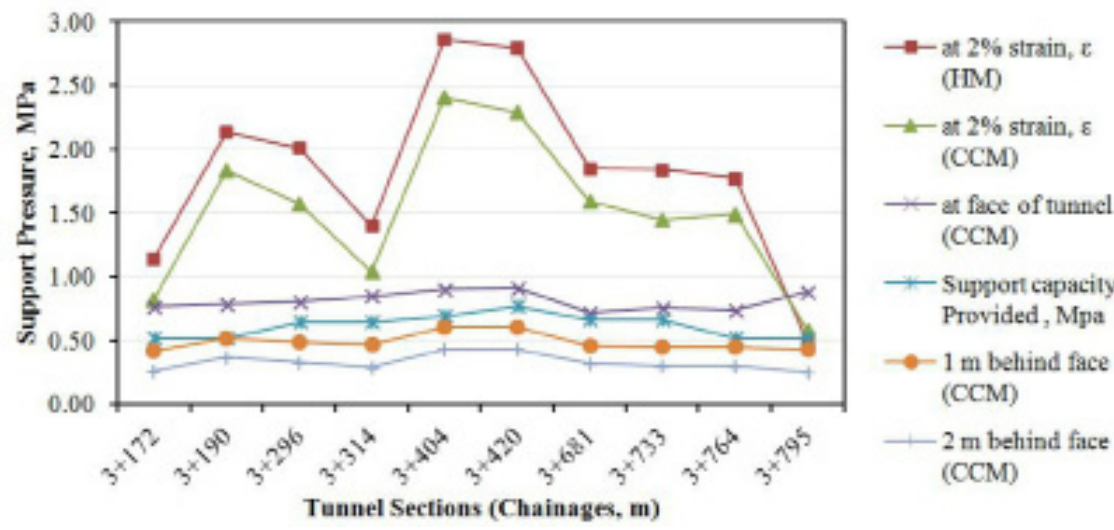

Figure 9. Estimated support pressure by three different approaches and applied support capacity

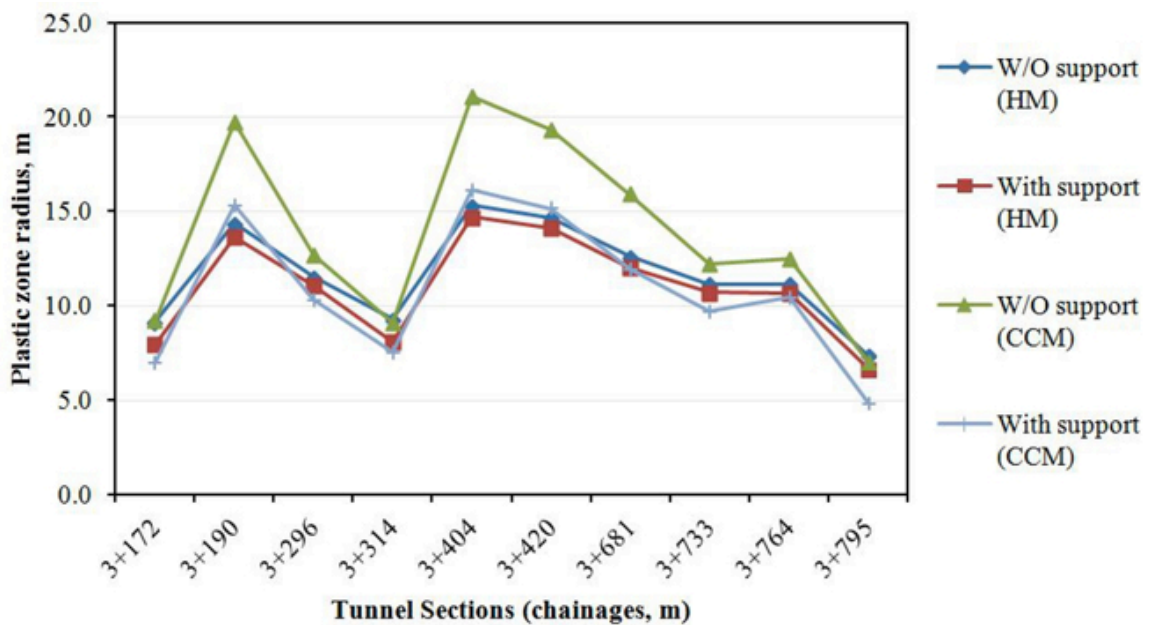

Figure 10. Plastic zone radius around the tunnel after excavation (with and without support) using $\mathrm{HM}$ and CCM approaches

behind tunnel face, respectively, using $2 \%$ tunnel strain condition and measured tunnel closures (Figure 9). In CCM, the critical support pressure has also been estimated. The critical support pressure means pressure at the point from which plastic behavior of rock material starts.

As indicated in Figure 10, the CCM gives greatest plastic zone radius when no support is used in the analysis. It is worthy to note that the greater the value of radius of plastic zone, the higher will be the resulting tunnel wall deformation.

The tunnel wall deformation analysis was carried out using both HM and CCM and corresponding tunnel strains are presented in Figure 11. All tunnel strain percentages are above $2 \%$ base line. Strain percentage at the face of the tunnel is, however, lowest for all tunnel sections but higher than the $2 \%$ base line. This illustrates that there is no possibility of maintaining the tunnel section within the specified tunnel strain percentage along this tunnel stretch with the use of flexible tunnel rock support.

The measured tunnel strain is more or less equal to the tunnel strain calculated by the HM approach with rock support consideration. However, the tunnel strain calculated by CCM with similar case as HM is slightly higher than the measured values. On the other hand, tunnel strain values at tunnel face, $1 \mathrm{~m}$ and $2 \mathrm{~m}$ behind the tunnel face are less than measured values. This illustrates that there is a need for rock supports with greater rigidity to restrain the excessive tunnel wall closure.

\section{Application of Phase $^{2}$ program in squeezing analysis}

After defining initial input parameters, HM approach is used to back calculate uniaxial compressive strength of intact rock and rock mass using actually measured deformation for four selected cases where 2D finite element numerical modeling has been conducted using Phase $^{2}$. Deformation values obtained from Phase $^{2}$ analysis is then compared to the findings calculated by HM, CCM and measured deformations. Some discrepancies have been found. Hence, the Phase $^{2}$ program was rerun for several times by 


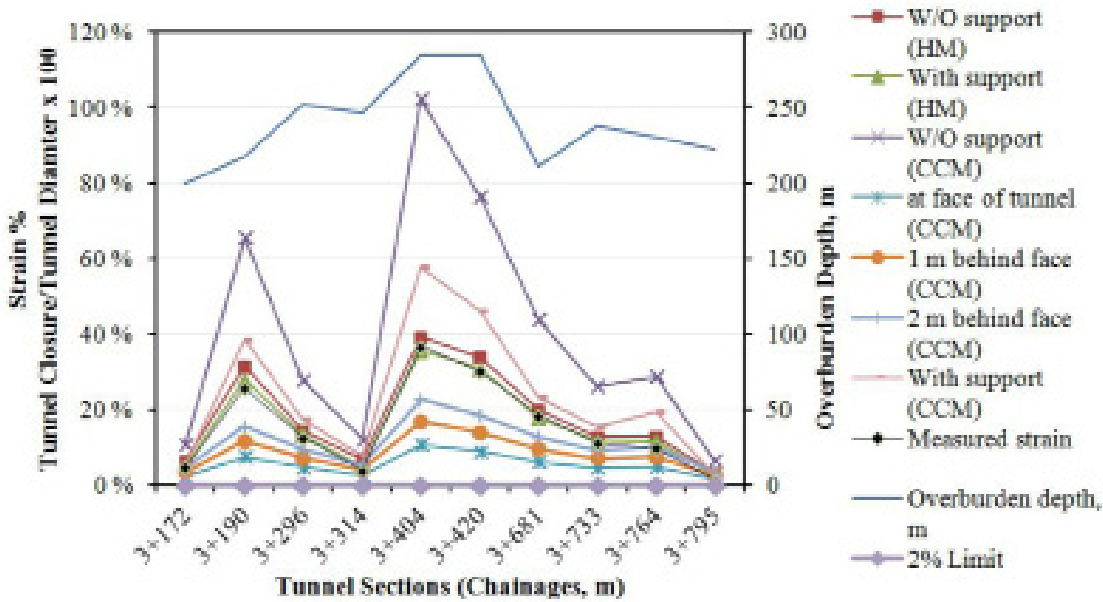

Figure 11. Comparison of tunnel strain percentage (with and without support) calculated using $\mathrm{HM}$ and $\mathrm{CCM}$ approaches with measured tunnel strain percentage and Marinos analysis shows lowest values for all four sections. CCM analysis shows that for two sections the results are more or less equal, but for other two sections, it gives relatively low values in comparison to actually measured values (Figure 13).

One of the main reasons for non-uniformity (discrepancy) in the results may be different assumptions that are exploited by each method. For example, HM analysis considers isostatic stress conditions and circular tunnel sections, while CCM considers the initial stress equal to the average of horizontal and vertical stress

changing rock mass parameters until the difference is within acceptable limit. The rock mass parameters that gave best result have been considered as improved and correct values. The procedure that was used for refining rock mass parameters is outlined in the form of flowchart in Figure 12.

The HM and CCM approaches have been used again using refined and corrected input variables to calculate tunnel deformation. The outputs obtained from different approaches are compared with each other and with measured values. Inputs to each method include the improved rock mass parameters. The analysis carried out with rock support indicate that Phase 2gives approximately equal to measured values whereas Hoek
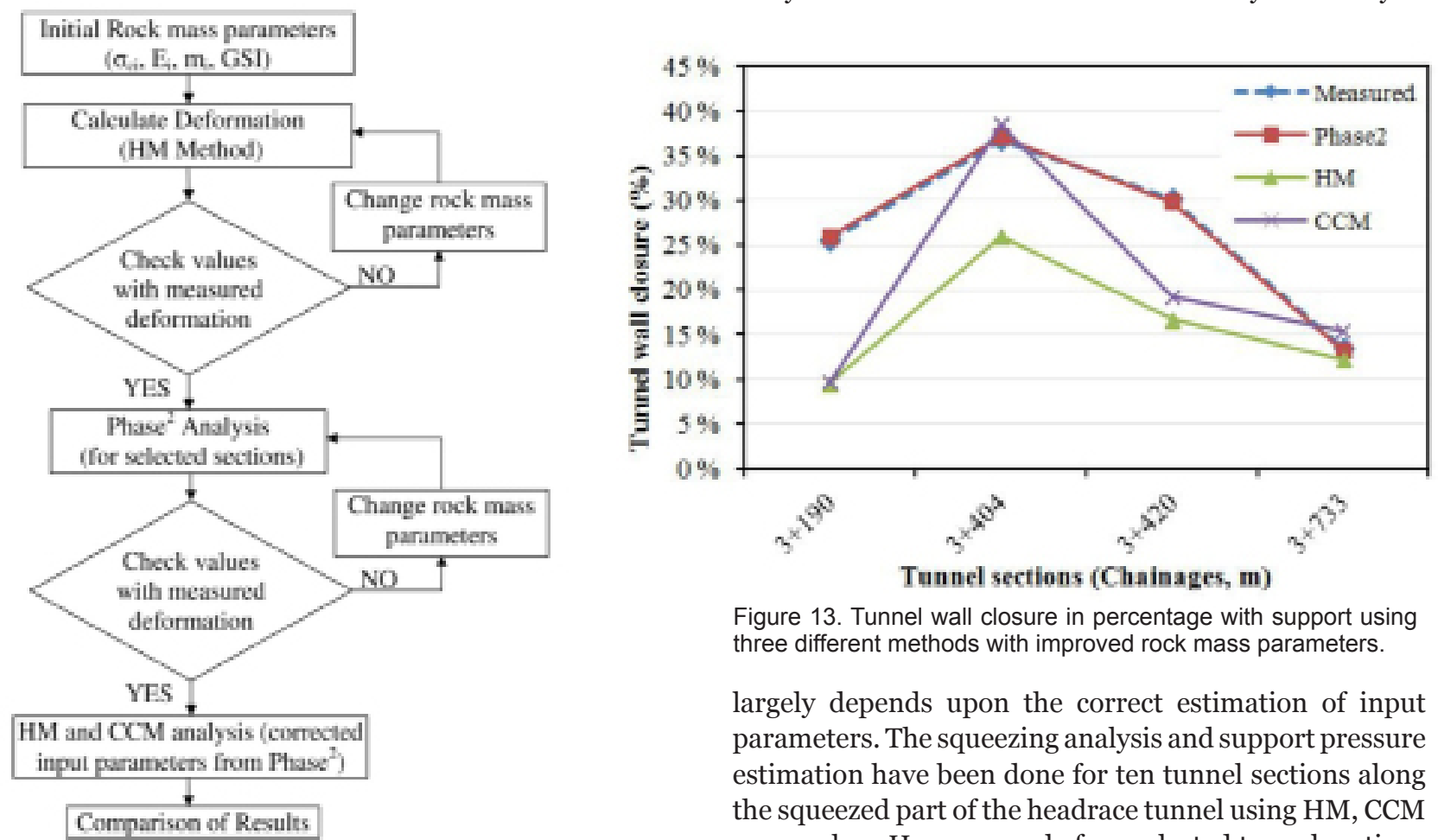

Figure 13. Tunnel wall closure in percentage with support using three different methods with improved rock mass parameters.

largely depends upon the correct estimation of input parameters. The squeezing analysis and support pressure estimation have been done for ten tunnel sections along the squeezed part of the headrace tunnel using HM, CCM approaches. However, only four selected tunnel sections were analyzed using Phase $^{2}$ numerical modeling. 
From analysis, it is found that back calculated rock mass parameters are slightly different from that estimated at the beginning. The back calculated value of intact rock strength is found to be in the range of 10 to $15 \mathrm{MPa}$ along the heavily squeezed headrace tunnel sections. The tunnel deformation is calculated using improved rock mass parameters as input to different approaches such as Hoek and Marinos, CCM and Phase ${ }^{2}$. The analysis also indicates that if carefully used it is possible to exploit all these three methodologies to evaluate the squeezing phenomenon. It should be emphasized that the input variables be carefully selected and that more than one methodology be used in predicting the severity of squeezing.

Chhatra Bahadur Basnet has MSc degree in Hydropower Development from the Norwegian University of Science and Technology (NTNU), Norway. He did his master thesis in rock engineering from the Department of Geology and Mineral Resources Engineering. He has more than five years of working experience in Planning, Design, and Construction Supervision of number of hydropower projects in Nepal. Corresponding Address: chhatra.basnet@gmail.com

Pawan Kumar Shrestha is conducting his PhD research at the Department of Geology and Mineral Resources Engineering, NTNU, Norway. He holds MSc degree in Hydropower Development from NTNU. He has more than 15 years of working experience in Construction management, Planning and Design of hydropower projects in Nepal.

Corresponding Address: pawan.k.shrestha@ntnu.no
Dr. Krishna Kanta Panthi is an Associate Professor in Geological Engineering at the Department of Geology and Mineral Resources Engineering, NTNU, since 2008. He holds degrees PhD in Rock Engineering, MSc in Hydropower Development and M Sc in Tunneling. He is the author of many scientific papers published from very renowned journals published internationally. He has more than 20 years of experience in research, design and construction supervision of tunneling, hydropower and slope stability projects.

Corresponding Address: krishna.panthi@ntnu.no

\section{References}

Basnet, C.B., 2013.Master's Thesis. Evaluation on the squeezing phenomenon at the headrace tunnel of Chameliya Hydroelectric Project in Nepal. NTNU, Trondheim, Norway.

Carranza-Torres, C. and Fairhurst, C., 200o. Application of the Convergence-Confinement method of tunnel design to rock masses that satisfy the Hoek-Brown failure criterion. Tunneling and Underground Space Technology, 15(2), 187-213.

Hoek, E., Carranza-Torres, C. and Corkum, B., 2002. Hoek-Brown Failure Criterion - 2002 Edition. Proceedings North American Rock Mechanics Society Meeting, Toronto, Canada, 1, 267-273.

Hoek, E. and Marinos, P., 2000. Predicting tunnel squeezing problems in weak heterogeneous rock masses. Tunnels and Tunneling International, 32(11), 45-51 and 32(11), 34-46.

Nepal Electricity Authority, 1997.Upgraded Feasibility Study, Chameliya Hydroelectric Project, Nepal, 1-98.

Panthi, K.K., 2006. Doctoral Thesis. Analysis of engineering geological uncertainties related to tunneling in Himalayan rock mass conditions, NTNU, Trondheim, Norway. 